\section{Research Square}

Preprints are preliminary reports that have not undergone peer review.

They should not be considered conclusive, used to inform clinical practice, or referenced by the media as validated information.

\title{
Comparison of the Clinical Characteristics of 2019 Novel Coronavirus Disease and Avian Influenza A (H1N1) Complicated with Acute Respiratory Distress Syndrome ${ }^{1}$
}

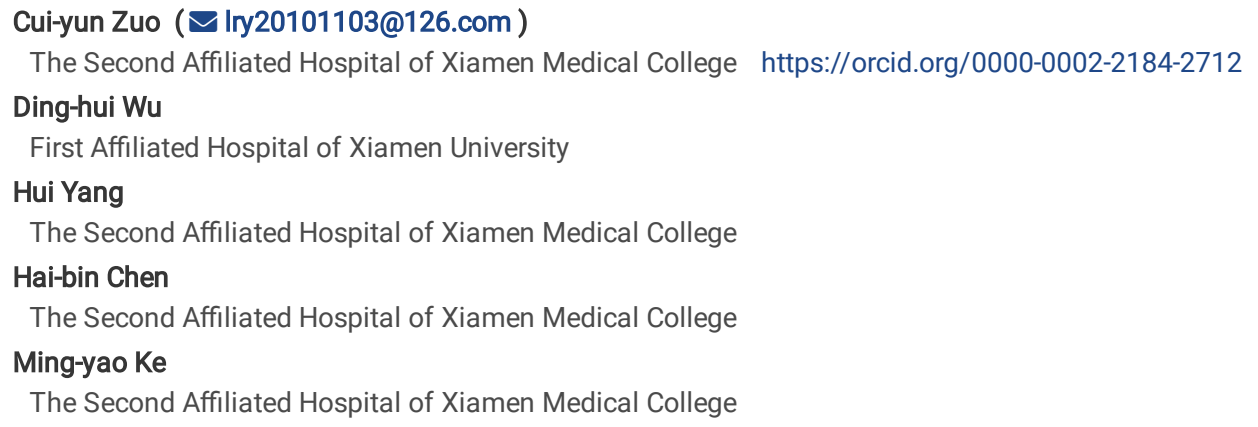

\section{Research}

Keywords: Acute respiratory distress syndrome, Avian influenza A, 2019 novel coronavirus disease (COVID-19), Severe acute respiratory syndrome coronavirus 2, Respiratory disease, Clinical outcome

Posted Date: March 19th, 2021

DOI: https://doi.org/10.21203/rs.3.rs-272045/v1

License: (c) (i) This work is licensed under a Creative Commons Attribution 4.0 International License. Read Full License 


\section{Abstract}

Objective: Both 2019 novel coronavirus disease (COVID-19) and avian influenza A (H1N1) are serious acute respiratory diseases with a predisposition to acute respiratory distress syndrome (ARDS). Our aim was to compare the clinical characteristics of patients with COVID-19 and H1N1 influenza complicated with ARDS.

Methods: We retrospectively studied data of 12 patients with ARDS (7 with COVID-19; 5 with H1N1 influenza) who were managed at The Second Affiliated Hospital of Xiamen Medical College and Xinglin Branch of the First Affiliated Hospital of Xiamen University between December 20, 2019 and February 29, 2020. We extracted the clinical information and outcomes from the hospital medical charts.

Results: Patients with COVID-19 were older and were more likely to have underlying diseases. Low-to-moderate fever was more frequent and upper respiratory tract symptoms were less common in COVID-19 patients. Chest computed tomography of patients with COVID-19 more frequently revealed bilateral nodular patchy ground-glass opacities in the subpleural and central lobular regions. Heart disorders and pleural effusion were less frequent, and coagulopathy was more common in patients with COVID-19. The average duration of stay in the respiratory intensive care unit was longer in patients with COVID-19. The disease severity and clinical outcomes did not differ significantly between the two groups.

Conclusion: Older age, higher comorbidity frequency, abnormal coagulation responses, longer hypoxemia duration, pulmonary fibrosis, and poorer clinical outcomes are the main characteristics in patients with COVID-19 who have ARDS. This calls for closer dynamic monitoring and more rigorous follow-up.

\section{Introduction}

The novel coronavirus disease (COVID-19) outbreak has rapidly spread worldwide, resulting in more than 6.5 million confirmed cases and more than 383,792 deaths worldwide as of June 5, 2020 (1). The mean case fatality rate of COVID-19 in mainland China was estimated to be $6.1 \%$ (2), which was significantly higher than that of other severe acute respiratory diseases, such as avian influenza A (H1N1;1.3\% in 2009), which has also been associated with global pandemics (3).

The clinical manifestations of COVID-19 are heterogeneous, ranging from mild to critical illness. Acute respiratory distress syndrome (ARDS) has been a common complication of both COVID-19 and H1N1 influenza in critically ill cases and is a crucial driver of respiratory failure or multiple organ dysfunction syndrome】the risk factors for death (4). However, it remains unclear whether the clinical characteristics and course of ARDS differ between patients with COVID-19 and those with H1N1 influenza.

To address this issue, we sought to compare the clinical characteristics of patients with ARDS associated with COVID-19 or with H1N1 influenza, to aid clinicians in identifying the defining characteristics of COVID-19.

\section{Methods}

This was a retrospective observational study. The study was approved by the ethics committee of both participating centers, and written informed consent was obtained from patients before enrollment. The procedures followed in our study were in accordance with the Declaration of Helsinki.

\section{Participants}

Between December 20, 2019 and February 29, 2020, we recruited patients who were admitted to the Respiratory department and respiratory intensive care unit (RICU) of the Second Affiliated Hospital of Xiamen Medical College and the Xinglin Branch of the First Affiliated Hospital of Xiamen University (the designated COVID-19 hospital of Xiamen City, China). All patients were diagnosed as having ARDS according to the Berlin criteria (5) and tested positive for either severe acute respiratory syndrome coronavirus 2 (SARS-CoV-2) or H1N1. All patients underwent H1N1 influenza virus and SARS-CoV-2 nucleic acid testing. SARSCoV-2 was tested using a reverse transcription polymerase chain reactionbased test on nasopharyngeal swabs. H1N1 influenza virus was tested using second- generation gene sequencing technology after hospital admission. We excluded patients younger than 14 years of age, those whose ARDS was caused by community-acquired pneumonia of unknown etiology, and those whose ARDS was due to known causes other than SARS-CoV-2 or H1N1. A total of 12 patients, including 7 patients with ARDS associated with COVID-19 and 5 patients with ARDS associated with H1N1 influenza virus infection, were admitted to our study sites.

\section{Clinical data collection}

We collected data on the sex, age, body mass index, underlying diseases, epidemiological history, clinical manifestations, laboratory examinations (at onset of ARDS), imaging examinations, treatment, and prognosis of the two groups of patients from the electronic medical record case system. The data were reviewed by a trained team of physicians.

\section{Statistical analysis}

The data were compared and analyzed descriptively, and the $\mathrm{P}$ values were not presented, because the sample size was too small for statistical analysis and subjects were not randomly collected. Mean \pm SD or median (interquartile range) was presented for the continuous variables, and count (percentage) was demonstrated for the description of categorical variables.

\section{Results}


As shown in Table 1, patients with COVID-19 were older than those with H1N1 influenza (median age: 56 vs. 43 years). None of the patients with H1N1 influenza (residents of Xiamen City) had any underlying diseases, whereas patients with COVID-19 had various underlying diseases, such as atrial fibrillation $(n=1)$, hypertension and obstructive sleep apnea syndrome $(n=1)$, diabetes $(n=1)$, diabetes and hypertension $(n=1)$, coronary artery disease and hypertension $(n=1)$, and malignancy $(n=1)$.

Five patients with COVID-19 were from Hubei province, and one was from Quanzhou City (Fujian province). Patients with H1N1 influenza had neither a recent travel history nor any family-based clusters of cases. The seven patients with COVID-19 had a clustered onset within a family.

Patients with COVID-19 presented with a significantly longer period from the onset of symptoms to ARDS development (7 vs. 4 days) and longer duration of stay in the RICU (mean, 18 vs. 14 days) than those with H1N1 influenza.

\section{Clinical manifestations upon development of ARDS}

Fever was the most common symptom, and low-to-moderate fever was significantly more common in patients with COVID-19 than in those with H1N1 influenza (85.7\% vs. 20.0\%). Upper respiratory tract symptoms were significantly less common in patients with COVID-19 than in those with $\mathrm{H} 1 \mathrm{~N} 1$ influenza (14.3\% vs. $80.0 \%)$; however, lower respiratory tract symptoms (including cough, chest tightness, and dyspnea) were exhibited by all patients in both groups. Hemoptysis was documented in two patients with H1N1 influenza but in none of the patients with COVID-19. Gastrointestinal tract symptoms were equally rare (Figure 1).

\section{Laboratory investigations upon development of ARDS}

In the ARDS stage, patients with COVID-19 were more likely to have abnormal coagulation than patients with H1N1 influenza, such as increased D-dimer levels (100.0\% vs. $20.0 \%$ ). However, patients with H1N1 were more likely to have abnormal cardiac function, such as increased myocardial injury markers (troponin I, $80.0 \%$ vs. $14.3 \%$ ) and increased heart failure indicators (brain natriuretic peptide, $80.0 \%$ vs. $14.3 \%$ ) than patients with COVID-19. Leukopenia, decreased albumin levels, and elevated C-reactive protein levels were common in both groups, as were lymphopenia and elevated serum transaminase levels (which occurred in all patients). In addition, hypoxemia was recorded in all patients (Table 2).

Blood culture results in all patients were negative. Only one case tested positive for mycoplasma antibodies (titer, 1:640). Of the five patients with H1 N1 influenza, two cases tested positive for Aspergillusfumigatus in galactomannan assays of bronchoalveolar lavage fluid.

\section{Imaging characteristics}

Computed tomography (CT) imaging showed that all patients with COVID-19 had multiple, bilateral lung lesions. In all cases, the lesions had a multi-lobar, multi-segmental distribution pattern (overlap between subpleural and lobular cores). Two cases showed ground-glass opacities only, while five cases had ground-glass opacities combined with consolidation. In all cases, there were nodular and patchy-type lesions. We also noted pleural parallel sign (6) in five cases, the fine-grid sign in six cases, the bronchogram sign in five cases, the vascular thickening sign in five cases, bronchiectasis in three cases, and the halo sign in two cases. There was a single case with anti-halo sign, one case with pleural effusion, and one case with pulmonary bulb. Representative images of patients with COVID-19 are shown in Figure 2.

On chest CT, all patients with H1N1 influenza had multiple lung lesions, all of which were diffusely distributed along the bronchial vascular bundle. All were ground-glass opacities with consolidation. All five cases showed bronchogram signs, three cases showed central leaflet nodules, three cases had a thickened leaflet septum and fine-mesh sign, and three cases presented with pleural effusion. Figure 3 shows the representative CT images of a patient with $\mathrm{H} 1 \mathrm{~N} 1$ influenza.

\section{Treatment and prognosis}

Antiviral drugs were initiated in all patients. Patients with COVID-19 received a-interferon nebulization, lopinavir/ritonavir, arbidol, ribavirin, and chloroquine phosphate according to the $4^{\text {th }}-7^{\text {th }}$ edition of the Pilot Program for the Diagnosis and Treatment of Novel Coronavirus Pneumonia (7-11). Patients with H1N1 influenza received systemic oseltamivir according to the Influenza Diagnosis and Treatment Plan 2019 Edition (12). Gamma immunoglobulin and anticoagulation therapy were initiated in patients with COVID-19, but only for a single patient with H1N1 influenza.

Nasal high-flow humidified oxygen therapy was initiated in four patients with COVID-19 (all had mild ARDS) and three patients with H1N1 (with mild-tomoderate ARDS). Alternating use of nasal high-flow humidifying oxygen therapy and non-invasive ventilator- assisted ventilation was initiated in three patients with COVID-19 due to moderate-to-severe ARDS, but in none of the patients with H1N1 influenza. Moreover, tracheal intubation with ventilator-assisted ventilation was initiated in two patients with H1N1 influenza (with severe ARDS), but in none of the patients with COVID-19.

Septic shock, thromboembolism, and renal insufficiency were absent in both groups. All patients had acquired pneumonia and abnormal liver function. Pneumothorax and mediastinal emphysema were found in a single patient with COVID-19, while gastrointestinal bleeding occurred in a case in each group. Myocardial damage and cardiac dysfunction were more common in the H1N1 group than in the COVID-19 group (80.0\% vs 14.3\%). Overall, patients with COVID-19 achieved viral assay conversion from clinical diagnosis in a significantly longer duration as compared with the patients with H1N1 influenza.

Furthermore, the duration of hypoxemia as well as the duration of stay in the RICU was longer in patients with COVID-19 (Table 3). None of the patients died throughout the course of our study due to timely clinical interventions. 


\section{Discussion}

There have been few reports of COVID-19 and H1N1 influenza complicated with ARDS to date. This study summarized the clinical characteristics, laboratory test results, and chest CT findings of the two diseases that might readily predispose to ARDS.

The seven patients with COVID-19 in our study formed a cluster of family cases, whereas all patients with H1N1 influenza were sporadic, suggesting that COVID-19 would be more contagious, with a stronger potential for human-to-human transmission $(4,12,13)$. Although the general population is susceptible, patients with COVID-19 in our study were mostly older and had underlying diseases, which was consistent with a previous report (14). Our findings showed that patients with COVID-19 were more likely to have low-to-moderate fever and minor upper respiratory tract symptoms than those with H1N1 influenza.

Our findings suggested that lymphopenia and liver dysfunction were common features of both diseases, while other laboratory tests differed between COVID19 and H1N1 influenza. For example, in patients with COVID-19, coagulopathy was more common (100\% vs. $20 \%$ ). The more serious the ARDS, the greater the increase in the D-dimer level, which was consistent with the reports by Chen et al (14). This mechanism was consistent with the pathological change of pulmonary microvascular transparent thrombosis after human infection with COVID-19 (15), which emphasized the need to closely monitor coagulation

dynamically and provide anti-coagulation treatment as early as possible in COVID-19 cases. In patients with H1N1 influenza, myocardial injury and cardiac dysfunction were more common (100\% vs. $20 \%$ ). The more serious the ARDS, the higher the level of troponin and brain natriuretic peptide (16), emphasizing the need for early recognition and treatment in patients with H1N1 influenza.

When comparing the results of blood gas analysis, we found that the duration of hypoxemia in patients with COVID-19 was longer. This may be related to the significant coagulation abnormality in the pulmonary microcirculation of COVID-19 patients (17). Our study showed that the period from diagnosis to achieving viral assay conversion in patients with COVID-19 was significantly longer than in patients with H1N1 influenza (average: 19 vs. 7 days). Taken together with a previous report (18), we speculated that the longer viral shedding time may cause more serious damage to the lung tissue and longer lasting hypoxemia, which may help explain why patients with COVID-19 had a longer stay in the RICU. This emphasizes the need for clinicians to manage COVID-19 patients with positive oxygen treatment measures in the early stage of hypoxemia (17).

In COVID-19 patients complicated with ARDS, the subpleural ground-glass opacities developed rapidly into bilateral diffuse infiltration or massive consolidation, often accompanied by the pleural parallel sign (100\%) and vascular thickening sign (71.4\%). Although the imaging manifestations of ARDS were similar, patients with H1N1 initially showed patchy ground-glass opacities, which were mainly distributed in the bronchovascular bundle (19, 20), and were accompanied by bronchiectasis (100\%), pleural effusion (60\%), and increased heart shadow (60\%). Therefore, the combination of the distribution of ground

glass opacities and the accompanying pleural parallel sign, enlarged heart shadows, and pleural effUsion sign would be of great value for the differential diagnosis. At the $3^{\text {rd }}$ month of follow-up, the chest CT showed that the lesions in patients with COVID-19 resolved slowly, and pulmonary fibrotic changes were more common in these cases (57.1\% vs. $13.3 \%)$. Therefore, pulmonary fibrosis after COVID-19 pneumonia cannot be ignored, and patients need close follow-up after discharge (21).

Overall, our patient population had a good prognosis, and no death was documented.

These findings might be partially explained by the inclusion of patients with mild-to- moderate ARDS in our study.

The interpretation of our findings was limited by the relatively small sample size and single-center retrospective study design. More multicenter prospective studies are needed in the future.

\section{Conclusions}

Patients with COVID-19 who had ARDS were older, were more likely to have comorbidities, and had higher incidences of abnormal coagulation and pulmonary fibrosis, a longer duration of hypoxemia, and poorer clinical outcomes than H1N1 patients with ARDS. Closer dynamic monitoring and rigorous follow-up should be implemented in patients with COVID-19 complicated with ARDS.

\section{Abbreviations}

AF, Atrial fibrillation; ALB, Albumin; ALT, Alanine aminotransferase; ARDS, Acute respiratory distress syndrome; AST, Aspartate aminotransferase; BNP, Brain natriuretic peptide; BUN, Blood urea nitrogen; CHD, Coronary heart disease; CK, Creatine kinase; CKMB, Creatine kinase isoenzyme; COVID-19, Coronavirus disease 2019; CRE, Creatinine; CRP, C-reactive protein; cTNI, Cardiac Troponin; D-D, D-dimer; ECMO, Extracorporeal membrane oxygenation; FiO ${ }_{2}$, Inhaled oxygen concentration; GM in BALF, Galactomannan in bronchoalveolar lavage fluid; HAP, Hospital-acquired pneumonia; HCG, Hemoglobin; LDH, Lactate dehydrogenase; LYM, Lymphocyte; MODS, Multiple organ dysfunction syndrome; NEU, Neutrophils; NFLO, Nasal high-flow oxygen therapy; NPC, Nasopharyngeal carcinoma; PaO2, Arterial partial pressure of oxygen; PCT, Procalcitonin; PLT, Platelet; RICU, Respiratory intensive care unit; VAP, Ventilatorassociated pneumonia; WBC, White blood cell;

\section{Declarations}

Ethics approval and consent to participate 
The study was approved by the ethics committee of both participating centers, and written informed consent was obtained from patients before enrollment. Ethical Approval of the Medical Ethics Committee of The Second Affiliated Hospital of Xiamen Medical College: Approval No:2020020区Ethical Approval of the First Affiliated Hospital of Xiamen University: Ethical approval document [2020] scientific research Lun Shen Zi (003).

\section{Consent for publication}

All presentations of case reports in the manuscript all have our institutional consent to publish.

\section{Data availability}

All data of our study are presented in this article.

\section{Funding}

This research did not receive any specific grant from funding agencies in the public, commercial, or not-for-profit sectors.

\section{Conflicts of interest}

The authors declare that they have no conflict of interest.

\section{Authors' contributions}

Data collection: $\mathrm{CZ}, \mathrm{HY}$, and $\mathrm{HC}$.

Study design: $\mathrm{CZ}, \mathrm{MK}$, and DW.

Analysis of data: $\mathrm{CZ}, \mathrm{HY}$, and $\mathrm{HC}$.

Manuscript preparation: All authors.

Review of manuscript: All authors.

\section{Acknowledgments}

We sincerely thank Prof. Wei-jie Guan (State Key Laboratory of Respiratory Disease, Guangzhou Institute of Respiratory Health, The First Affiliated Hospital of Guangzhou Medical University), and Dr. Xiao-bin Zhang (Department of Pulmonary and Critical Care Medicine, Xiamen University, Teaching Hospital of Fujian Medical University) for his help with the manuscript.

\section{References}

1. National Health Commission Update [Internet]. [cited ]. Available from: http://www.nhc.gov.cn/xcs/yqfkdt/202002/d5c495da742f4739b7f99339c3bd032f.shtml. Accessed on June 5, 2020.

2. Mi YN, Huang TT, Zhang JX, et al. Estimating the instant case fatality rate of COVID-19 in China. Int J Infect Dis 97:1-6, 2020.

3. Writing Committee of the WHO Consultation on Clinical Aspects of Pandemic (H1N1) 2009 Influenza, Bautista E, Chotpitayasunondh T, et al. Clinical aspects of pandemic 2009 influenza a (H1N1) virus infection. N Engl J Med 362:1708-1719, 2010. Erratum in: N Engl J Med 362:2039, 2010.

4. She J, Jiang J, Ye L, Hu L, Bai C, Song Y. 2019 Novel coronavirus of pneumonia in Wuhan, China: Emerging attack and management strategies. Clin Transl Med 9:19, 2020.

5. ARDS Definition Task Force, Ranieri VM, Rubenfeld GD, et al. Acute respiratory distress syndrome: the Berlin Definition. JAMA 307:2526-2533, 2012.

6. Wu J, Feng CL, Xian XY, et al. Novel coronavirus pneumonia (COVID-19) CT distribution and sign features. Zhonghua Jie He He Hu Xi Za Zhi 43:321-326, 2020 (in Chinese, Abstract in English).

7. General Office of the National Health Commission, office of the State Administration of traditional Chinese medicine. Diagnosis and treatment of novel coronavirus pneumonia (trial version fourth). Guo Wei ban Yi Han 77:1-10, 2020.

8. General Office of the National Health Commission, office of the State Administration of traditional Chinese medicine. Diagnosis and treatment of novel coronavirus pneumonia (trial version fifth). Guo Wei ban Yi Han 103:1-12, 2020.

9. General Office of the National Health Commission, office of the State Administration of traditional Chinese medicine. Diagnosis and treatment of novel coronavirus pneumonia (trial version sixth). Guo Wei ban Yi Han 145:1-16, 2020.

10. General Office of the National Health Commission, office of the State Administration of traditional Chinese medicine. Diagnosis and treatment of novel coronavirus pneumonia (trial version seventh). Guo Wei ban Yi Han 182:1-24, 2020.

11. General Office of the National Health Commission, office of the State Administration of traditional Chinese medicine. Influenza diagnosis and treatment plan (2019 version). Guo Wei ban Yi Han 819:1-15, 2019.

12. Huang C, Wang Y, Li X, et al. Clinical features of patients infected with 2019 novel coronavirus in Wuhan, China. Lancet 395:497-506, 2020.

13. Wang D, Hu B, Hu C, et al. Clinical characteristics of 138 hospitalized patients with 2019 novel coronavirus-infected pneumonia in Wuhan, China. JAMA 323:1061-1069, 2020. 
14. Chen N, Zhou M, Dong X, et al. Epidemiological and clinical characteristics of 99 cases of 2019 novel coronavirus pneumonia in Wuhan, China: a descriptive study. Lancet 395:507513, 2020.

15. Guan WJ, Ni ZY, Hu Y, et al. Abnormal coagulation parameters are associated with poor prognosis in patients with novel coronavirus pneumonia. N Engl J Med 382:1708-1720, 2020.

16. Chacko B, Peter JV, Pichamuthu K, et al. Cardiac manifestations in patients with pandemic (H1N1) 2009 virus infection needing intensive care. J Crit Care 27:106.e1-6, 2012.

17. Li HC, Ma J, Zhang H, et al. Thinking and practice on novel coronavirus pneumonia treatment for severe cases. Chin J Tuberc Respir Di 43:396-400, 2020.

18. Li H, Weng H, Lan C, et al. Comparison of patients with avian influenza A (H7N9) and influenza A (H1N1) complicated by acute respiratory distress syndrome. Medicine (Baltimore) 97:e0194, 2018.

19. Rohani P, Jude CM, Chan K, Barot N, Kamangar N. Chest radiological findings of patients with severe H1N1 pneumonia requiring intensive care. J Intens Care Med 31:51-60, 2016.

20. Lobo SM, Watanabe ASA, Salomao MLM, et al. Excess mortality is associated with influenza A (H1N1) in patients with severe acute respiratory illness. J Clin Virol 116:62-68, 2019.

21. Zhan X, Liu B, Tong ZH. Postinflammatory pulmonary fibrosis of COVID-19: the current status and perspective. Zhonghua Jie He He Hu Xi Za Zhi 43:728732,20

\section{Tables}

Table 1. General Information and Epidemiological Characteristics upon the Development of ARDS 


\begin{tabular}{|c|c|c|c|c|c|c|c|c|c|c|c|c|}
\hline & \multicolumn{7}{|c|}{ COVID-19 } & \multicolumn{5}{|c|}{ H1N1 influenza } \\
\hline & Case 1 & $\begin{array}{l}\text { Case } \\
2\end{array}$ & Case 3 & Case 4 & Case 5 & Case 6 & Case 7 & Case 1 & Case 2 & $\begin{array}{l}\text { Case } \\
3\end{array}$ & $\begin{array}{l}\text { Case } \\
4\end{array}$ & Case 5 \\
\hline Age (years) & 75 & 36 & 44 & 71 & 64 & 67 & 36 & 47 & 53 & 47 & 21 & 45 \\
\hline Sex & Male & Male & Male & Male & Female & Female & Male & Male & Male & Male & Male & Male \\
\hline Occupation & $\begin{array}{l}\text { Retired } \\
\text { worker }\end{array}$ & $\begin{array}{l}\text { Taxi } \\
\text { driver }\end{array}$ & $\begin{array}{l}\text { Restaurant } \\
\text { owner }\end{array}$ & $\begin{array}{l}\text { Retired } \\
\text { worker }\end{array}$ & $\begin{array}{l}\text { Retired } \\
\text { worker }\end{array}$ & $\begin{array}{l}\text { Retired } \\
\text { worker }\end{array}$ & Businessperson & $\begin{array}{l}\text { Wood } \\
\text { worker }\end{array}$ & Farmer & Driver & Clerk & $\begin{array}{l}\text { Renovati } \\
\text { worker }\end{array}$ \\
\hline $\begin{array}{l}\text { Date of } \\
\text { admission }\end{array}$ & $\begin{array}{l}\text { Feb 6, } \\
2020\end{array}$ & $\begin{array}{l}\text { Jan } \\
28 \\
2020\end{array}$ & $\begin{array}{l}\text { Jan 30, } \\
2020\end{array}$ & $\begin{array}{l}\text { Feb 7, } \\
2020\end{array}$ & $\begin{array}{l}\text { Jan 24, } \\
2020\end{array}$ & $\begin{array}{l}\text { Jan 28, } \\
2020\end{array}$ & Jan 22, 2020 & $\begin{array}{l}\text { Jan 1, } \\
2020\end{array}$ & $\begin{array}{l}\text { Jan } \\
23 \\
2019\end{array}$ & $\begin{array}{l}\text { Jan } \\
18 \\
2020\end{array}$ & $\begin{array}{l}\text { Jan } \\
11 \\
2020\end{array}$ & $\begin{array}{l}\text { Feb 3, } \\
2020\end{array}$ \\
\hline $\begin{array}{l}\text { Time from } \\
\text { onset to } \\
\text { ARDS (days) }\end{array}$ & 2 & 6 & 7 & 2 & 7 & 7 & 5 & 3 & 4 & 4 & 5 & 5 \\
\hline $\begin{array}{l}\text { Severity of } \\
\text { ARDS }\end{array}$ & Mild & Mild & Mild & Mild & Moderate & Severe & Severe & Moderate & Mild & Severe & Severe & Mild \\
\hline $\begin{array}{l}\text { Time to stay } \\
\text { in RICU } \\
\text { (days) }\end{array}$ & 16 & 15 & 12 & 14 & 24 & 25 & 17 & 11 & 8 & 23 & 11 & 10 \\
\hline $\begin{array}{l}\text { Body-mass } \\
\text { index }\end{array}$ & 31.4 & 32.5 & 23.4 & 20.2 & 28.6 & 26.6 & 24.6 & 21.4 & 26.3 & 30.2 & 26.8 & 26.2 \\
\hline \multicolumn{13}{|c|}{ Epidemiological characteristics } \\
\hline $\begin{array}{l}\text { Permanent } \\
\text { residents of } \\
\text { Hubei or } \\
\text { Wuhan }\end{array}$ & Yes & No & Yes & Yes & Yes & No & No & No & No & No & No & No \\
\hline $\begin{array}{l}\text { Having been } \\
\text { to Hubei or } \\
\text { Wuhan } \\
\text { within } 2 \\
\text { weeks }\end{array}$ & Yes & No & Yes & Yes & Yes & Yes & Yes & No & No & No & No & No \\
\hline $\begin{array}{l}\text { Close } \\
\text { contact with } \\
\text { patients with } \\
\text { COVID-19 } \\
\text { within } 2 \\
\text { weeks }\end{array}$ & Yes & Yes & Yes & Yes & Yes & Yes & Yes & No & No & No & No & No \\
\hline $\begin{array}{l}\text { Family } \\
\text { cluster }\end{array}$ & Yes & Yes & Yes & Yes & Yes & Yes & Yes & No & No & No & No & No \\
\hline \multicolumn{13}{|l|}{ Comorbidities } \\
\hline $\begin{array}{l}\text { Heart } \\
\text { disease }\end{array}$ & AF & No & No & No & $\mathrm{CHD}$ & No & No & No & No & No & No & No \\
\hline Hypertension & No & Yes & No & Yes & Yes & No & No & No & No & No & No & No \\
\hline Diabetes & No & No & Yes & Yes & No & No & No & No & No & No & No & No \\
\hline Malignancy & No & No & No & No & No & NPC & No & No & No & No & No & No \\
\hline $\begin{array}{l}\text { Obstructive } \\
\text { sleep apnea } \\
\text { syndrome }\end{array}$ & No & Yes & No & No & No & No & No & No & No & No & No & No \\
\hline
\end{tabular}

AF: atrial fibrillation, ARDS: acute respiratory distress syndrome, CHD: coronary heart disease, COVID-19: novel coronavirus disease, H1N1 influenza: avian influenza A, NPC: nasopharyngeal carcinoma, RICU: respiratory intensive care unit

Due to technical limitations, table 2 is only available as a download in the Supplemental Files section.

Table 3. Laboratory Test Findings upon the Development of ARDS 


\begin{tabular}{|c|c|c|c|c|c|c|c|c|c|c|c|c|c|}
\hline & \multirow{2}{*}{$\begin{array}{l}\text { Normal } \\
\text { range }\end{array}$} & \multicolumn{7}{|c|}{ COVID-19 Group } & \multicolumn{5}{|l|}{ H1N1 Group } \\
\hline & & Case 1 & $\begin{array}{l}\text { Case } \\
2\end{array}$ & $\begin{array}{l}\text { Case } \\
3\end{array}$ & Case 4 & $\begin{array}{l}\text { Case } \\
5\end{array}$ & $\begin{array}{l}\text { Case } \\
6\end{array}$ & $\begin{array}{l}\text { Case } \\
7\end{array}$ & Case 1 & $\begin{array}{l}\text { Case } \\
2\end{array}$ & Case 3 & Case 4 & $\begin{array}{l}\text { Case } \\
5\end{array}$ \\
\hline WBC $\left(\times 10^{9} / \mathrm{L}\right)$ & $3.5-9.5$ & 5.05 & 1.92 & 6.22 & 9.71 & 2.72 & 2.94 & 4.16 & 1.93 & 4.42 & 6.38 & 3.12 & 2.68 \\
\hline $\operatorname{NEU}\left(\times 10^{9} / \mathrm{L}\right)$ & $1.8-6.3$ & 3.78 & 1.13 & 5.06 & 9.07 & 1.71 & 2.32 & 3.52 & 1.53 & 3.6 & 5.34 & 2.59 & 1.82 \\
\hline NEU (\%) & $50-70$ & 74.9 & 58.9 & 81.3 & 93.5 & 62.9 & 79 & 84.5 & 79.5 & 81.4 & 83.7 & 83.1 & 67.9 \\
\hline $\operatorname{LYM}\left(\times 10^{9} / \mathrm{L}\right)$ & $1.1-3.2$ & 0.77 & 0.68 & 0.48 & 0.5 & 0.73 & 0.46 & 0.41 & 0.17 & 0.49 & 0.59 & 37.44 & 0.67 \\
\hline LYM (\%) & $20-50$ & 15.2 & 35.3 & 7.7 & 5.1 & 26.8 & 15.6 & 9.9 & 9 & 11.1 & 9.3 & 12 & 25 \\
\hline $\operatorname{PLT}\left(\times 10^{9} / \mathrm{L}\right)$ & $\begin{array}{l}125- \\
350\end{array}$ & 139 & 154 & 193 & 121 & 88 & 144 & 266 & 83 & 103 & 156 & 123 & 112 \\
\hline $\mathrm{Hb}(\mathrm{g} / \mathrm{L})$ & $\begin{array}{l}115- \\
150\end{array}$ & 158 & 133 & 125 & 133 & 126 & 111 & 149 & 137 & 121 & 150 & 125 & 138 \\
\hline ALT (U/L) & $9-50$ & 43 & 58 & 32 & 63 & 87 & 99 & 70 & 54.8 & 75.5 & 70.2 & 205 & 40 \\
\hline AST (U/L) & $15-40$ & 42 & 46 & 44 & 97 & 73 & 52 & 84 & 161.6 & 146 & 184.6 & 77 & 49 \\
\hline $\operatorname{ALB}(\mathrm{g} / \mathrm{L})$ & $40-55$ & 26 & 30 & 24 & 22 & 24 & 27 & 28 & 25.59 & $26 . .12$ & 24.86 & 35.06 & 31 \\
\hline $\mathrm{CRE}(\mu \mathrm{mol} / \mathrm{L})$ & $\begin{array}{l}62- \\
115\end{array}$ & 87 & 65 & 94 & 97 & 76 & 54 & 56 & 89 & 99 & 74 & 29.9 & 92 \\
\hline BUN (mmol/L) & $2.9-8.2$ & 5.31 & 1.97 & 6.85 & 4.85 & 3.68 & 3.88 & 6.15 & 6.6 & 5.1 & 4.9 & 4.74 & 3.44 \\
\hline CK (IU/L) & $\begin{array}{l}38- \\
174\end{array}$ & 331 & 186 & 106 & 152 & 75 & 122 & 165 & 160 & 47 & 4648 & 303 & 1027 \\
\hline CKMB (U/L) & $0-24$ & 17 & 9 & 10 & 13 & 28 & 5 & 18 & 17.7 & 19 & 81.3 & 31 & 17 \\
\hline cTNI (ng/mL) & $\leq 0.04$ & 0.021 & 0.01 & 0.036 & 0.038 & 0.04 & 0.68 & 0.018 & 0.075 & 13.08 & 2.643 & 6.105 & 0.012 \\
\hline $\mathrm{BNP}(\mathrm{pg} / \mathrm{mL})$ & $<100$ & 52 & 35 & 86 & 92 & 68 & 151 & 58 & 105 & 108 & 310.89 & 1953.70 & 46 \\
\hline LDH (IU/L) & $\begin{array}{l}91- \\
180\end{array}$ & 244 & 326 & 148 & 248 & 144 & 354 & 231 & 862 & 409 & 885 & 381 & 687 \\
\hline CRP (mg/L) & $0-8$ & 127.64 & 19.62 & 26.8 & 122.66 & 88.9 & 77.5 & 68 & 222.83 & 118 & 109.45 & 83.8 & 18.9 \\
\hline РСТ (ng/mL) & $0-0.1$ & 0.20 & 0.15 & 0.07 & 0.45 & 0.05 & 0.12 & 0.23 & 1.152 & 0.338 & 0.247 & 1.084 & 0.13 \\
\hline \multicolumn{14}{|l|}{$\mathrm{PaO}_{2} / \mathrm{FiO}_{2}$} \\
\hline $200-300$ & 300 & 248 & 203 & 295 & 287 & & & & & 245 & & & 236 \\
\hline $100-200$ & & & & & & 186 & & & 189 & & & & \\
\hline$<100$ & & & & & & & 78 & 86 & & & 78.5 & 80 & \\
\hline D-D (mg/L) & $0-0.55$ & 0.972 & 0.830 & 0.728 & 2.104 & 0.693 & 2.896 & 2.568 & 0.53 & 0.258 & 4.132 & 0.394 & 0.453 \\
\hline $\begin{array}{l}\text { Nasopharynx } \\
\text { test influenza A }\end{array}$ & $(-)$ & $(-)$ & $(-)$ & $(-)$ & $(-)$ & $(-)$ & $(-)$ & $(-)$ & NA & NA & NA & NA & NA \\
\hline $\begin{array}{l}\text { Nasopharynx } \\
\text { test influenza B }\end{array}$ & $(-)$ & $(-)$ & $(-)$ & $(-)$ & $(-)$ & $(-)$ & $(-)$ & $(-)$ & NA & NA & NA & NA & NA \\
\hline $\begin{array}{l}\text { Influenza A virus } \\
\text { IgM }\end{array}$ & NA & NA & NA & NA & NA & NA & NA & NA & $(-)$ & $(-)$ & $(-)$ & $(+)$ & $(-)$ \\
\hline $\begin{array}{l}\text { Mycoplasma } \\
\text { pneumoniae } \\
\text { antibody IgM }\end{array}$ & $<1: 40$ & $1: 640$ & $<1: 40$ & $<$ & $<1: 40$ & $<$ & $<1: 40$ & $<1: 40$ & $<1: 40$ & $<1: 40$ & $<1: 40$ & $<1: 40$ & $<1: 40$ \\
\hline $\begin{array}{l}\text { Chlamydia } \\
\text { pneumoniae } \\
\text { antibody IgM }\end{array}$ & $(-)$ & $(-)$ & $(-)$ & $(-)$ & $(-)$ & $(-)$ & $(-)$ & $(-)$ & $(-)$ & $(-)$ & $(-)$ & $(-)$ & $(-)$ \\
\hline $\begin{array}{l}\text { Alveolar lavage } \\
\text { fluid smear and } \\
\text { culture }\end{array}$ & $(-)$ & NA & NA & NA & NA & NA & NA & NA & $\begin{array}{l}\text { Aspergillus } \\
\text { fumigatus }\end{array}$ & $(-)$ & $\begin{array}{l}\text { Aspergillus } \\
\text { fumigatus }\end{array}$ & $(-)$ & $(-)$ \\
\hline GM in BALF & $(-)$ & NA & NA & NA & NA & NA & NA & NA & $(+)$ & $(-)$ & $(+)$ & $(-)$ & $(-)$ \\
\hline
\end{tabular}

ALB: albumin, ALT: alanine aminotransferase, ARDS: acute respiratory distress syndrome, AST: aspartate aminotransferase, BNP: brain natriuretic peptide, BUN: blood urea nitrogen, CK: creatine kinase, CKMB: creatine kinase isoenzyme, COVID-19: novel coronavirus disease, CRE: creatinine, CRP: C-reactive protein, 
cTNI: troponin, D-D: D-dimer, GM in BALF: galactomannan in alveolar lavage fluid, H1N1 influenza: avian influenza A, Hb: hemoglobin, LDH: lactate dehydrogenase, LYM: lymphocyte, NA: not available, NEU: neutrophils, PCT: procalcitonin, PLT: platelet, WBC: white blood cell

Table 4. Treatment and Prognosis upon the Development of ARDS 


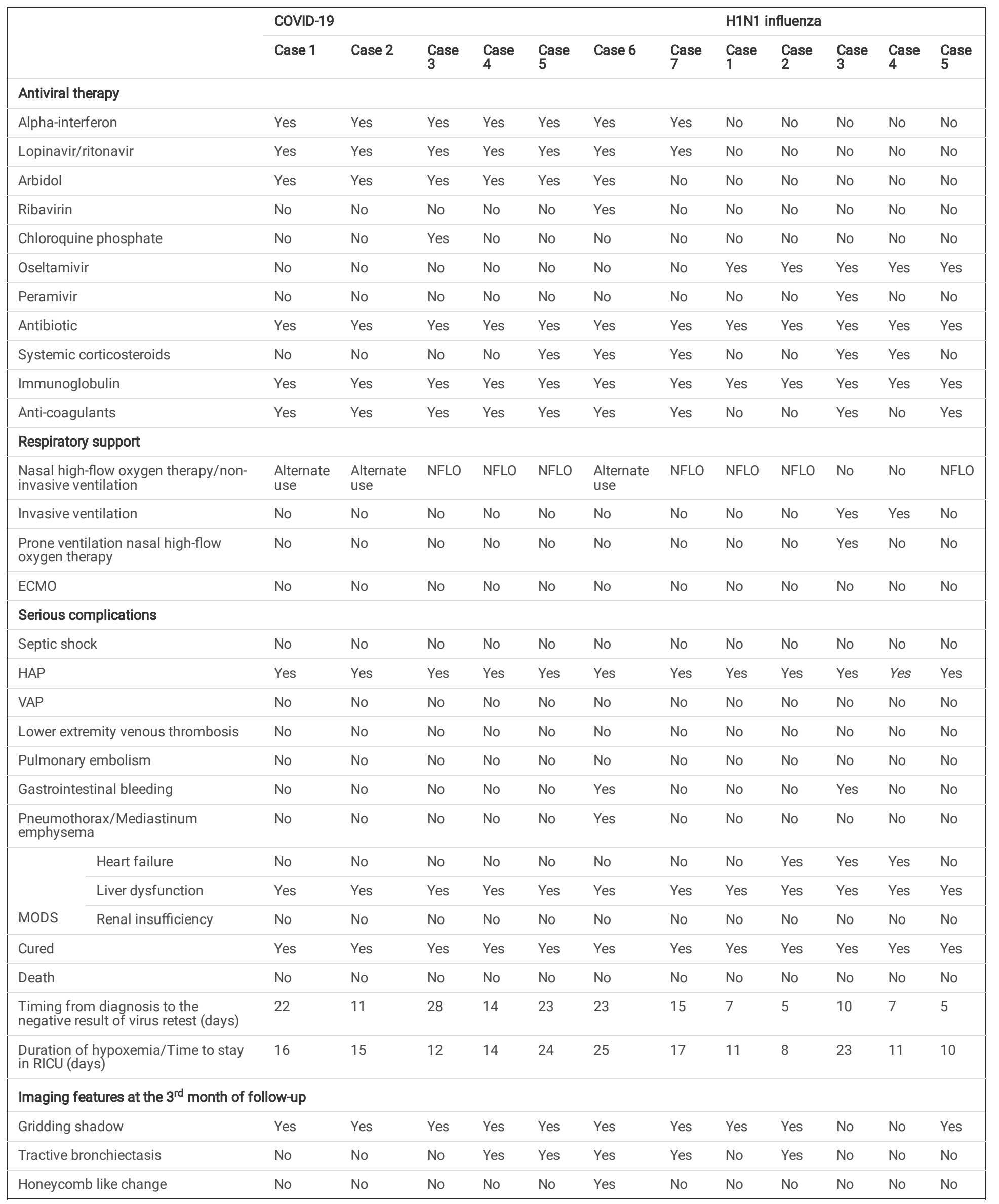

COVID-19: novel coronavirus disease, ECMO: extracorporeal membrane oxygenation, H1N1 influenza: avian influenza A, HAP: hospital-acquired pneumonia, MODS: multiple organ dysfunction syndrome, NFLO: nasal high-flow oxygen therapy, RICU: respiratory intensive care unit, VAP: ventilator-associated pneumonia 


\section{Figures}
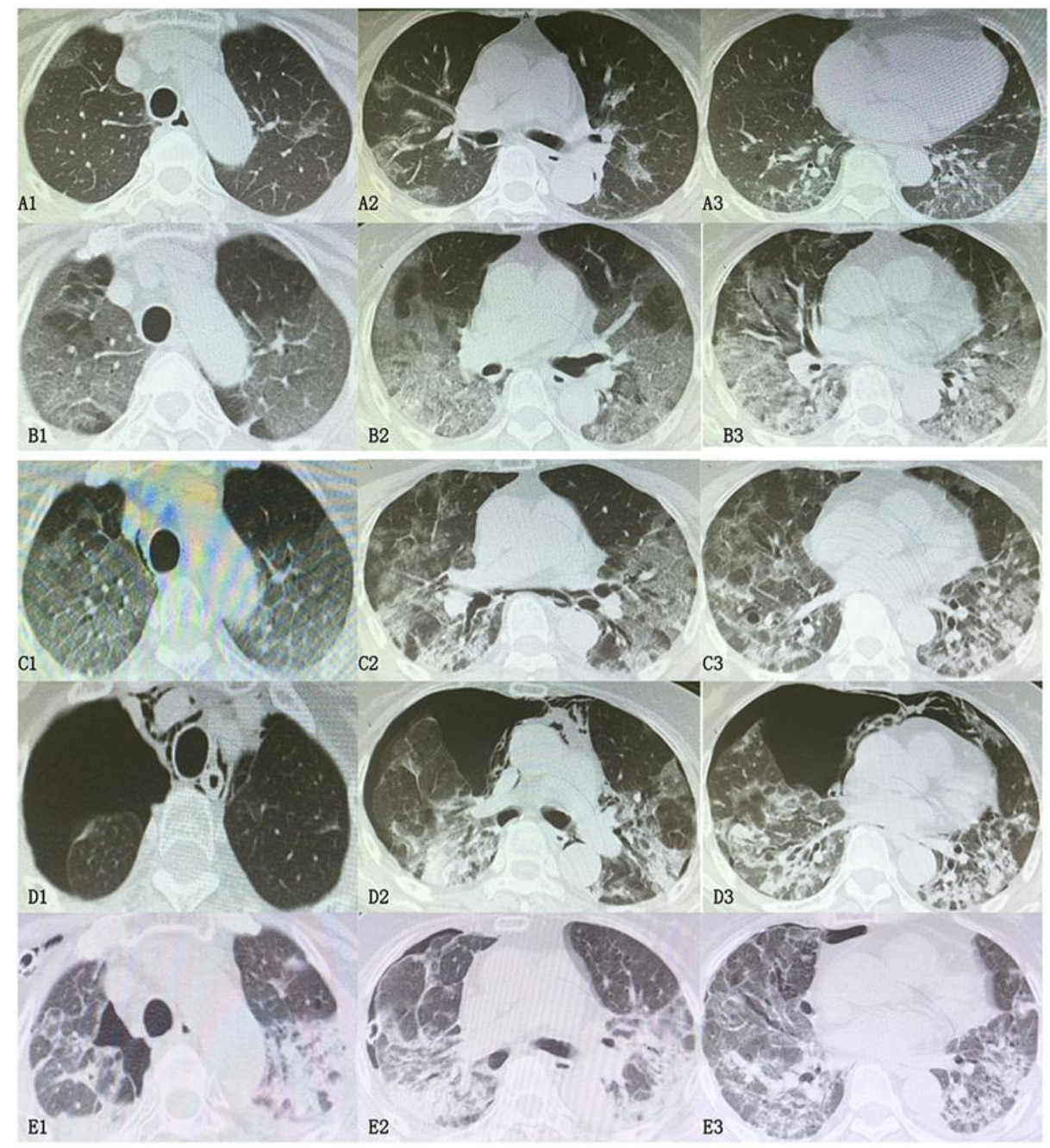

Figure 1

Computed tomography images in Case 6 (COVID-19 group). Shown are the images from a 67-year-old female who had advanced chemotherapy and chemotherapy for nasopharyngeal cancer, presenting with chills, fever, and cough for 1 week. A1-A3: chest computed tomography images immediately on admission (January 28, 2020): multiple subpleural and lobular core lesions are mainly nodular and patchy ground glass opacities. B1-B3 (February 9, 2020): rapidly progressing lesion (fused lesion with diffuse exudation). C1-C3 (February 13, 2020): extended ground glass opacity density. D1-D3 (February 18, 2020): bilateral pneumothorax. E1-E3 (February 29, 2020): left pneumothorax fully absorbed and the mediastinal emphysema disappeared despite minor pneumothorax visible in the right lung. 

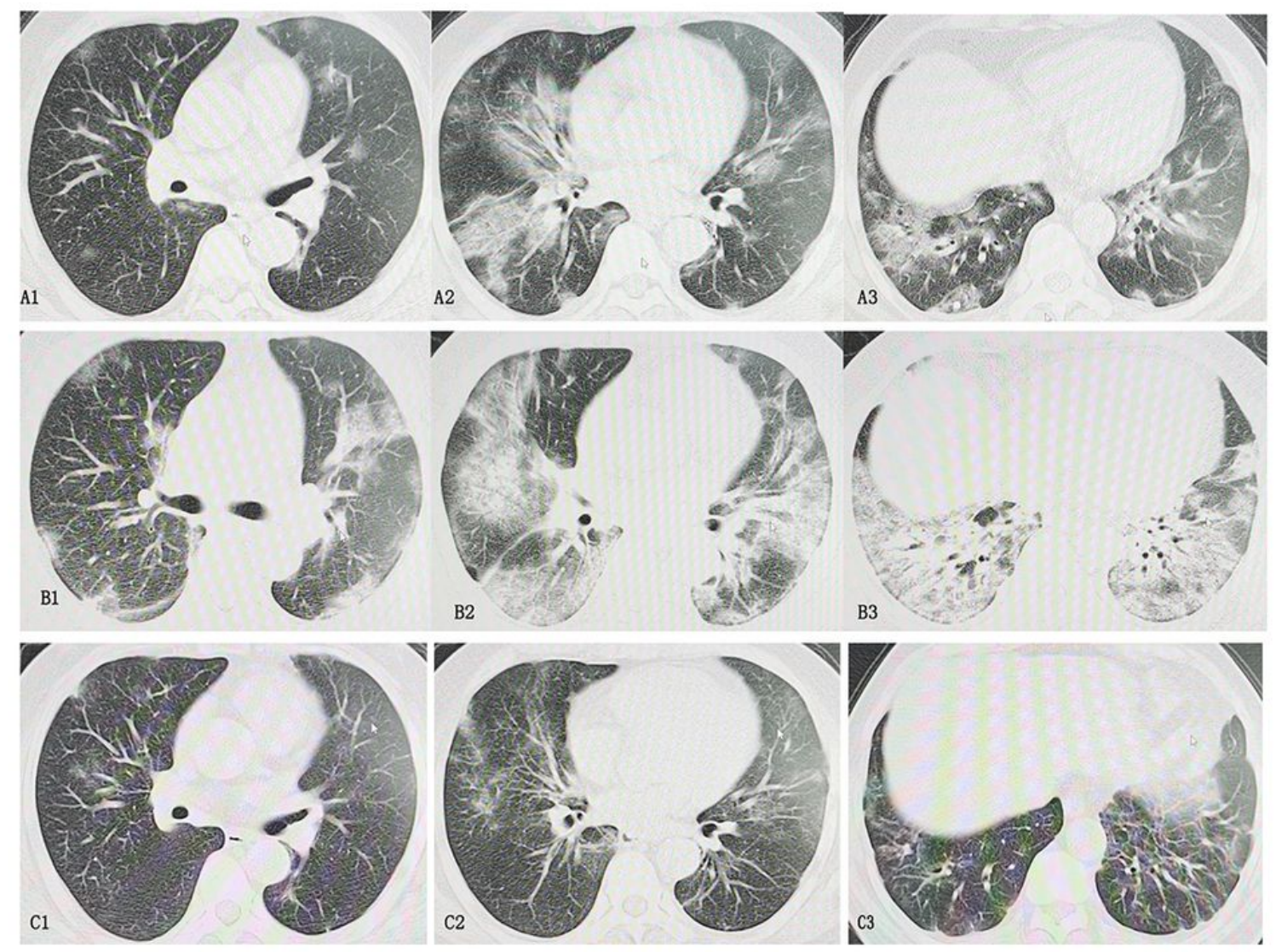

\section{Figure 2}

Representative chest computed tomographic imaging characteristics in a patient with H1N1 influenza infection (Case 2). Shown are the radiographic manifestations of a previously otherwise healthy 53-year-old male with cough, fever, chest tightness, and dyspnea. A1-A3: chest images obtained at admission (December 23, 2019): multiple irregular ground-glass opacities distributed along the bronchial vascular bundles. B1-B3 (December 26, 2019): Rapidly progressing pulmonary lesions with major ground-glass opacities and consolidation, particularly in the middle and lower lung. C1-C3 (February 27 , 2020): Significantly absorbed ground-glass opacities in both lungs.

\section{Supplementary Files}

This is a list of supplementary files associated with this preprint. Click to download.

- Table2.jpg 